\title{
The Relationship among Test Anxiety, Self-Efficacy, and Writing Performance Among Iranian Intermediate EFL Learners
}

\author{
Saeide Majidifar ${ }^{1}$, Mohammad Reza Oroji ${ }^{2, *}$ \\ ${ }^{1}$ Department of English, Zanjan Branch, Islamic Azad University, Zanjan, Iran \\ ${ }^{2}$ Assistant Professor, Department of English, Zanjan Branch, Islamic Azad University, Zanjan, Iran
}

Email address:

mohammadrezaoroji@yahoo.com (M. R. Oroji)

\section{To cite this article:}

Saeide Majidifar, Mohammad Reza Oroji. The Relationship among Test Anxiety, Self-Efficacy, and Writing Performance Among Iranian Intermediate EFL Learners. International Journal of Language and Linguistics. Vol. 3, No. 6, 2015, pp. 323-327.

doi: $10.11648 /$ j.ij11.20150306.11

\begin{abstract}
Writing performance in general plays a significant part in any academic field and it is a flexible tool that can be used to meet a variety of goals (Diamond, 1999; Graham, 2006b). This study aimed to illuminate and investigate the two psychological and crucial factors influencing the writing performance: Self-efficacy (SE) and Test anxiety (TA). An attempt was made to assess the relationship among Self-efficacy, Test anxiety and writing performance. In so doing, after homogenizing the students as Intermediate ones via a placement test, two questionnaires of SE ( Owen \&Froman,1988 ) and Test anxiety (Suinn, 1969) were administered to 50 intermediate students. Having administered the questionnaires, the researcher asked the subjects to compose an essay on a general topic: 'The effects of TV on people's lives'. Based on the questionnaires, the subjects were divided into four groups: 1) High SE, High TA, 2) High SE, Low TA, 3) Low SE, High TA, and 4) Low SE, Low TA. The data collected from the questionnaires as well as the scores given to their writing performances were analyzed through SPSS (21.00). Results indicated that there were statistically significant differences between the two groups of High self-efficacy, low test anxiety and Low self-efficacy, high test anxiety. The former group outperformed the latter one. The outcomes of this study can have benefits for both foreign language teachers and learners. They both can attain better results by focusing more on these two psychological factors in their roles. The findings of the present study demonstrated that more concentration ought to be placed on these two psychological factors in order to enhance students' writing performances.
\end{abstract}

Keywords: Self-Efficacy, Test Anxiety, Writing Performance

\section{Introduction}

Educational researchers are interested in different variables that affect the success/ failure of the learners in their task performance. Learner's performance in tests or examinations is one of the significant variables that gauge a student's success or failure in academic or school activities. The goal of every educational program is to make certain that the learners attain an acceptable and successful outcome (good writing performance). One of the main and the natural distress for an educational scientist is to make a good and non-nerve-racking environment to make students achieve success. Test anxiety is one of the important hindrances to reaching this goal. Feelings of anxiety toward test have existed for many years and are hurdles that influence the writing performance of learners. Different learners have different levels of anxiety, which bring about a variety of negative writing performance results.

The other noticeable variable in this area is the student's sense of self as a principal component of task performance (Pajares \& Schunk, 2001). Studies show that one's own beliefs of efficacy are an important determinant of motivation, thought, and action (Bandura, 1997). Learners with high self-efficacy and high self-confidence in their skills can control and decrease the negative effect of anxiety on their writing performance (Bandura, 1986, 1997). To achieve success, the learners with low efficacy do not search for the opportunities to obtain skills and knowledge which are requisite to be a successful learner. One reason for this is that these individuals see themselves as 
unintelligent.

The purpose of this study was to investigate the relationship among self- efficacy, test anxiety, and writing performance among EFL learners. This study aimed at finding out to what extent self-efficacy and test- anxiety would affect EFL learners' writing ability in a test or examination. Based on the results of the study, one may conclude that affective factors seem to play a more important role in the performance of learners.

The present study could contribute to solving the problems of EFL teachers and learners in decreasing the amount of test anxiety by introducing the extreme source of fear of negative evaluation. The findings of this study would help the EFL learners to find out how they could conduct the best writing performance in their tests without stress. The results of this study could provide insights to help EFL learners to reduce their test anxiety and increase the level of their confidence. The outcomes could also make learners capable enough to estimate their efficacy in their test. Unlike the previous studies, this research established a firm connection among test anxiety, self-efficacy and test writing performance.

\section{Research Questions}

Based on the purpose and significance of the study, the research questions were as follows:

1) Is there any significant relationship between Intermediate EFL students' level of self-efficacy and their writing performance?

2) Is there any significant relationship between Intermediate EFL students' level of test anxiety and their writing performance?

3) Is there any significant relationship between Intermediate EFL students' writing performance and the interactional effect of their self-efficacy and test anxiety?

\section{Null Hypotheses}

H01. There is no significant relationship between Intermediate EFL students' level of self-efficacy and their writing performance.

H02. There is no significant relationship between Intermediate EFL students' level of test anxiety and their writing performance.

H03. There is no significant relationship between Intermediate EFL students' writing performance and the interactional effect of their self-efficacy and test anxiety.

\section{Participants, Procedure, and Design}

The participants were 50 BA EFL students (male and female) at Islamic Azad University of Zanjan and were selected on the basis of convenience sampling. Having been homogenized via a proficiency test (Cambridge Placement Test, 2010), 32 students were selected as intermediate ones.
Their age ranged between 19 and 28. A standard questionnaire of test anxiety by Suinn (1969) was distributed among the participants in the present study to achieve their general test anxiety. Subsequently, in order to measure the participants' level of SE in this study, Owen and Froman (1988) scale was utilized.

Afterwards, one general topic was introduced to the students and they were asked to compose an essay on it. The reason why this topic was given to the subject was that the participants were required to write essays without any prior preparation and beforehand knowledge. Two experienced TEFL university professors, with a very high command of English, were later asked to score the students' writing performances on the basis of the rubric which is special for writing assessment. Each essay was scored on the basis of the five scales of "Task Achievement", "Coherence and Cohesion", "Lexical Resource", "Grammatical Range", and "Accuracy". Based on the collected data, four groups were formed:

1. High TA - high SE group

2. High TA- low SE group

3. Low TA - low SE group

4. Low TA - high SE group

This research examined the relationship among a writing performance and test anxiety and self-efficacy. Two dependent (Test Anxiety and Self-Efficacy) and one independent variable (writing performance) were examined in this study. The design of the study was ex-post facto design.

\section{Data Analysis}

After filling out the questionnaires, the participants were categorized into four different groups. It was necessary to know that they all had the same degree of proficiency. A oneway ANOVA was run to compare the means of the groups on the proficiency test in order to prove that they enjoyed the same level of general language proficiency prior to the main study. Based on the results displayed in Table 1 (F $(3,28)$ $=.341, \mathrm{P}>.05)$, it can be concluded that there were not any significant differences between means of the four groups on the proficiency test. Thus, it can be claimed that they enjoyed the same level of general language proficiency prior to the main study.

Table 1. One-Way ANOVA Proficiency by Groups.

\begin{tabular}{llllll}
\hline & $\begin{array}{l}\text { Sum of } \\
\text { Squares }\end{array}$ & Df & $\begin{array}{l}\text { Mean } \\
\text { Square }\end{array}$ & F & Sig. \\
\hline $\begin{array}{l}\text { Between } \\
\text { Groups }\end{array}$ & 123.500 & 3 & 40.177 & .341 & .784 \\
$\begin{array}{l}\text { Within } \\
\text { Groups }\end{array}$ & 3290.722 & 28 & 117.525 & & \\
Total & 3414.222 & 31 & & & \\
\hline
\end{tabular}

A Pearson correlation was run to probe any significant relationship between self-efficacy and writing performance. Based on the results displayed in Table 2 ( $\mathrm{r}(30)=.72, \mathrm{P}$ $<.05$ representing a large effect size) it can be concluded that 
there was a significant and large correlation between selfefficacy and writing performance. Thus, the first nullhypothesis was rejected.

Table 2. Pearson Correlation; Self-Efficacy with Writing Performance.

\begin{tabular}{lll}
\hline & & Writing \\
\hline \multirow{3}{*}{ Self-Efficacy } & Pearson Correlation & $.722^{* *}$ \\
& Sig. (2-tailed) & .000 \\
& $\mathrm{~N}$ & 32 \\
\hline
\end{tabular}

**. Correlation is significant at the 0.01 level (2-tailed).

A Pearson correlation was run to probe any significant relationship between test anxiety and writing performance.
Based on the results displayed in Table $3(\mathrm{r}(30)=.51, \mathrm{P}$ $<.05$ representing a large effect size) it can be concluded that there was a significantly negative and large correlation between test anxiety and writing performance. Thus, the second null-hypothesis was rejected.

Table 3. Pearson Correlation; Test Anxiety with Writing Performance.

\begin{tabular}{lll}
\hline & & Writing \\
\hline \multirow{3}{*}{ Test Anxiety } & Pearson Correlation & $-.512^{* *}$ \\
& Sig. (2-tailed) & .003 \\
& $\mathrm{~N}$ & 32 \\
\hline
\end{tabular}

**. Correlation is significant at the 0.01 level (2-tailed).

Table 4. Descriptive Statistics; Writing Performance by Groups.

\begin{tabular}{|c|c|c|c|c|c|c|c|c|}
\hline & \multirow{2}{*}{$\mathbf{N}$} & \multirow{2}{*}{ Mean } & \multirow{2}{*}{ Std. Deviation } & \multirow{2}{*}{ Std. Error } & \multicolumn{2}{|c|}{ 95\% Confidence Interval for Mean } & \multirow{2}{*}{ Minimum } & \multirow{2}{*}{ Maximum } \\
\hline & & & & & Lower Bound & Upper Bound & & \\
\hline HSEHANX & 7 & 4.29 & .994 & .376 & 3.37 & 5.21 & 3 & 6 \\
\hline HSELANX & 10 & 7.20 & .715 & .226 & 6.69 & 7.71 & 6 & 8 \\
\hline LSEHANX & 6 & 4.00 & .707 & .289 & 3.26 & 4.74 & 3 & 5 \\
\hline LSELANX & 9 & 4.94 & 1.044 & .348 & 4.14 & 5.75 & 3 & 6 \\
\hline Total & 32 & 5.33 & 1.569 & .277 & 4.76 & 5.89 & 3 & 8 \\
\hline
\end{tabular}

HSEHANX = high self-efficacy and high anxiety, HSELANX = high self-efficacy and low anxiety, LSEHANX = low self-efficacy and high anxiety and LSELANX = low self-efficacy and low anxiety.

Table 5. One-Way ANOVA; Writing Performance by Groups.

\begin{tabular}{|c|c|c|c|c|c|c|}
\hline \multirow{2}{*}{ (I) Group } & \multirow{2}{*}{ (J) Group } & \multirow{2}{*}{ Mean Difference (I-J) } & \multirow{2}{*}{ Std. Error } & \multirow{2}{*}{ Sig. } & \multicolumn{2}{|c|}{ 95\% Confidence Interval } \\
\hline & & & & & Lower Bound & Upper Bound \\
\hline \multirow[t]{2}{*}{ HSEHANX } & LSEHANX & .286 & .490 & .952 & -1.17 & 1.74 \\
\hline & HSEHANX & $2.914^{*}$ & .434 & .000 & 1.62 & 4.21 \\
\hline \multirow[t]{2}{*}{ HSELANX } & LSEHANX & $3.200^{*}$ & .455 & .000 & 1.85 & 4.55 \\
\hline & LSELANX & $2.256^{*}$ & .405 & .000 & 1.05 & 3.46 \\
\hline LSELANX & HSEHANX & .659 & .444 & .541 & -.66 & 1.98 \\
\hline
\end{tabular}

*. The mean difference is significant at the 0.05 level.

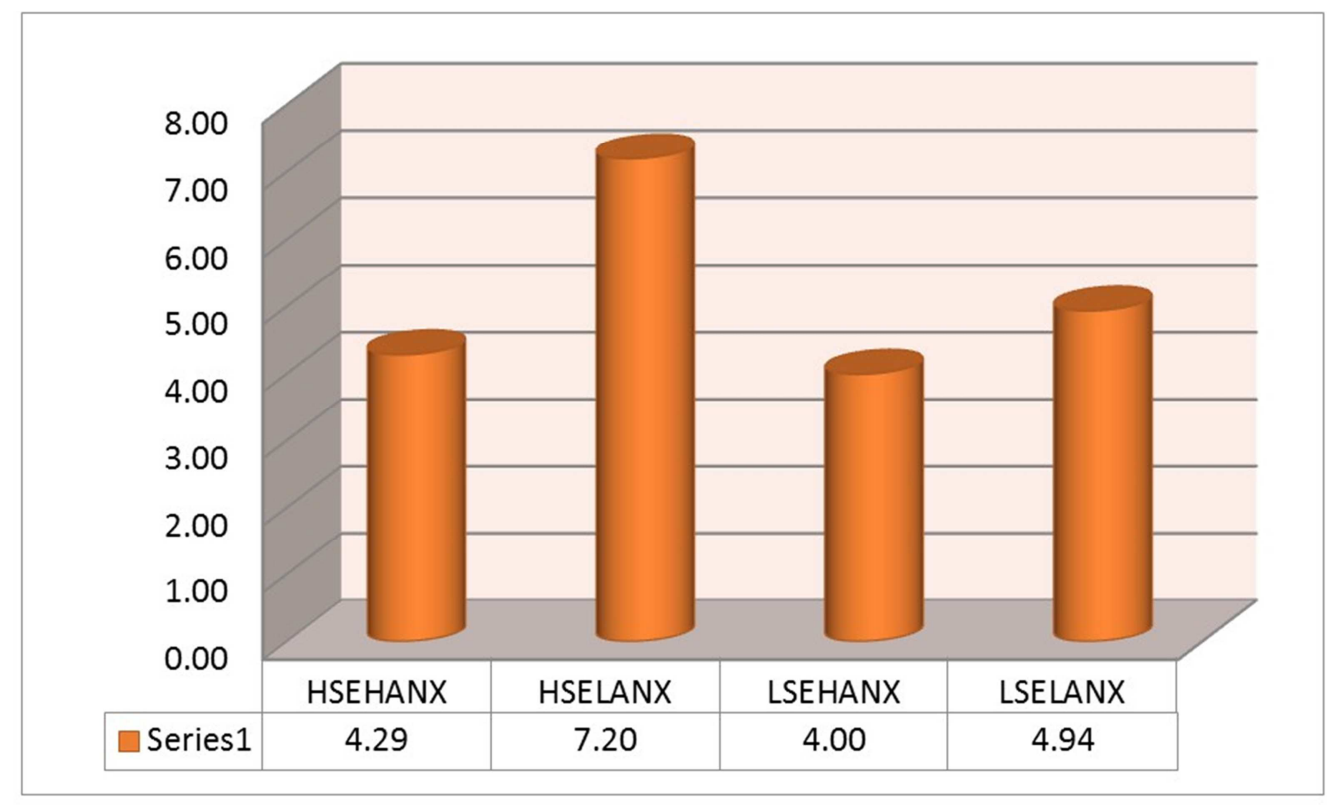

Graph 1. Writing Performance by Groups. 
A one-way ANOVA was run to compare the four groups' means on the writing performance in order to probe the third research question. Based on the results displayed in Table 4 it can be concluded that the high self-efficacy low anxiety (HSELANX) showed the highest mean on writing performance $(\mathrm{M}=7.20, \mathrm{SD}=.71)$. This was followed by low self-efficacy low anxiety (LSELANX) $(\mathrm{M}=4.94, \mathrm{SD}=1.04)$, high self-efficacy high anxiety (HSEHANX) $(\mathrm{M}=4.29$, SD $=.99)$ and low self-efficacy low anxiety (LSELANX) $(\mathrm{M}=4$, $\mathrm{SD}=.70)$.

The one-way ANOVA results $(\mathrm{F}(3,28)=23.40, \mathrm{P}<.05$, $\omega 2=.67$ representing a large effect size) indicated that there were significant differences between the means of the four groups on the writing performance. Thus, the third nullhypothesis was rejected.

Although the F-value of 23.40 indicated significant differences between the means of the four groups, the posthoc Scheffe's tests should be run to compare the means two by two. Based on the results displayed in Table 4 it can be concluded that; A: The high self-efficacy and low anxiety group $(\mathrm{M}=7.20)$ outperformed the high self-efficacy and high anxiety group $(\mathrm{M}=4.29)$ on the writing performance $(\mathrm{MD}=2.91, \mathrm{P}<.05)$.

B: The high self-efficacy and low anxiety group $(\mathrm{M}=7.20)$ outperformed the low self-efficacy and high anxiety group $(\mathrm{M}=4)$ on the writing performance $(\mathrm{MD}=3.20, \mathrm{P}<.05)$.

$\mathrm{C}$ : The high self-efficacy and low anxiety group $(\mathrm{M}=7.20)$ outperformed the low self-efficacy and low anxiety group (M $=4.94)$ on the writing performance $(\mathrm{MD}=2.25, \mathrm{P}$ $<.05)$. There were not any significant differences between the other pairs of means $(\mathrm{P}>.05)$.

\section{Discussion and Conclusions}

The analysis demonstrated that students with high test anxiety outperformed the students with low test anxiety. Both test anxiety and self-efficacy played an important role in students' writing skill. Although, according to Chapell et al. (2005) test anxiety has negative correlation with academic performance, we must add that self-efficacy can play a principal role as well. Low test anxiety alone is not enough for students to deliver satisfying writing performances. In this research, cases with high test anxiety were observed to have problems such as heart contraction, increasing the pulse rate, blood pressure, body temperature, blood sugar, stomach acid, enlargement of the pupil of the eyes, difficult breathing, muscle tension and sweating (Hollandsworth, Glazeski, Kirkland, Jones, \& Van Norman, 1979; Holroyd, Westbrook, Wolf, \& Badhorn, 1978) while taking tests. However, those utilizing the high quality of self-efficacy and low quality of test anxiety didn't face such difficulties in their performances

This study was in line with Sarason's (1975) findings that test anxiety is negatively associated with writing performance. Sarason (1984) claimed that the test-anxious person experiences worry, insecurity, and self-doubt in evaluative situations. These internal factors decrease attention to the task at hand and lead to poor performance.

This study proved that as Chapell et al. (2005) realized, test anxiety has negative correlation with academic performance. In addition, this study proved that self-efficacy can play a principal role as well. Low test anxiety alone is not enough for students to deliver satisfying writing performances.

This study was also consistent with the Spielberger and Vagg (1995) and Zeidner's (1998) findings that test anxiety can impair performance, it means there is a direct relationship between test anxiety and students' writing performance in EFL context.

This study was also in agreement with Zeidner's (1998) outcomes that "test-anxious students tend to be easily distracted on an exam, experience difficulty in comprehending relatively simple instructions, and also have difficulty organizing or recalling relevant information during the test" (p. 4).

The current study was in agreement with the analysis of the studies of Horwitz, 2001; MacIntyre and Gardner, 1994. DeDeyn (2011) claimed that there is a negative relationship between anxiety and measures of performance in language classrooms, such as task scores, test scores, or final exam grades.

The findings of this research were also in line with Linnenbrink and Pintrich (2003). Students low in selfefficacy tend to exhibit self-doubts and give up easily when confronted with difficulties, even if they have the skills or knowledge to perform the task. Such students also tend to focus on grades rather than learning as the goal of performance, and, when given the opportunity, they choose moderately easy tasks about which they have confidence of success (Walker, 2003).

According to outcome of this study as Betz and Hackett (1983) and Krampen (1988) assert, people with high perceived self-efficacy in writing are less likely to be immobilized by anxiety.

As it is crystal clear, by considering group 2 (high selfefficacy students with low level of test anxiety), it can be claimed that having a high self-efficacy and low test anxiety can guarantee the high quality of writing performance. In sum, it must be emphasized that the interaction of both variables of high self-efficacy and low test anxiety has positive effects on writing performance of students.

According to post-hoc Scheffe's test results, it can be asserted that the group which outperformed the others was group one with high self-efficacy and low test anxiety students $(\mathrm{M}=7.20)$. That means the interaction of two variables (self-efficacy and test anxiety) resulted in acceptable writing performance. Therefore, the interaction or joint effect of both high self-efficacy and low test anxiety has had a positive impact on students' writing performance.

As it is obvious, the interaction of both High self-efficacy and low test anxiety has led to the best performance among all. The lowest record was gained by the high test anxiety and Low Self-efficacy group. So the highest self-efficacy and the 
lowest test anxiety, the best writing performance. The interaction of these two psychological factors empowers students to control and overcome the fear of writing.

\section{References}

[1] Bandura, A. (1997). Self-efficacy: The exercise of control. New York: Freeman.

[2] Bandura, A., (1986). Social foundations of thought and action: A social cognitive view. Eaglewood Cliffs: Prentice Hall.

[3] Betz, N. E., \& Hackett, G. (1983). The relationship of mathematics self-efficacy expectations to the selection of science-based college majors. Journal of Vocational Behavior, 23, 329-345.

[4] Chapell, M. S., Blanding, Z. B., Silverstein, M. E., Takahashi, M., Newman, B., Gubi, A., \&McCann, N. (2005). Test anxiety and academic performance in undergraduate and graduate students. Journal of Educational Psychology, 97(2), 268-274.

[5] DeDeyn, R. (2011). Student identity, writing anxiety, and writing performance: A correlational study (Master's thesis). Available from ProQuest Dissertations and Theses database.

[6] Diamond, J. (1999). Guns, germs, and steel: The fates of human societies. New York: Norton.

[7] Graham, S. (2006b). Writing. In P. Alexander \& P. Wiine (Eds.), Handbook of educational psychology (pp. 457-477). Mahwah, NJ: Erlbaum.

[8] Hollandsworth, Glazeski, Kirkland, Jones, \& Van Norman. (1979). An analysis of the nature and effects of test anxiety: Cognitive, behavioral, and physiological components. Cognitive Therapy and Research 3 (2), 165-180.

[9] Holroyd, K. A., Westbrook, T., Wolf, M. \& Badhorn, E. (1978). Performance, cognition, and physiological responding to test anxiety. Cognitive Therapy and Research, 3, 165-180.

[10] Horwitz, E. K. (2001). Language anxiety and achievement. Annual Review of Applied Linguistics, 21, 112 - 126.
[11] Krampen, G. (1988). Competence and control orientations as predictors of test anxiety in students: Longitudinal results. Anxiety Research, 1, 185-197.

[12] Linnenbrink, E. A., \& Pintrich, P. R. (2003). The role of selfefficacy beliefs in student engagement and learning in the classroom. Reading and Writing Quarterly, 19, 119-137.

[13] MacIntyre, P. D. \& Gardner, R. C. (1989). Anxiety and second language leaning: Toward a theoretical clarification. Language Learning 39, 251-275.

[14] MacIntyre, P. D., \& Gardner, R. C. (1994). The subtle effects of language anxiety on cognitive processing in the second language. Language Learning, 44(2), 283-305.

[15] Owen, S. V., \& Froman, R. D. (1988). Development of a College Academic Self-Efficacy Scale.

[16] Pajares F. \& Shunk D. H. (2001). Self-beliefs and school success: self- efficacy, self-concept and school achievement. In R. Riding \& S. Rayner (Eds.) Perception (pp.239-266). London: Albex publishing.

[17] Sarason, I. G. (1984), Stress, anxiety, and cognitive interference: Reactions to Tests. Journal of Personality and Social Psychology, 46 (4), 929-938.

[18] Sarason, I. G. (1975). The test anxiety scale: Concept and research. In I. G. Sarason, \& C. D. Spielberger (Eds.), Stress and anxiety (pp.193-217). Washington, DC: Hemisphere.

[19] Spielberger, C. D. \& Vagg, P. R. (1995). Test anxiety: A Transactional Process Model. In Spielberger et al. (Eds), Test anxiety: Theory, assessment, and treatment (pp. 1-14). Taylor \& Francis.

[20] Suinn, R. M. (1969). The STABS, a measure of test anxiety for behavior therapy: Normative data. Behavior Research and Therapy, 7, 335-339.

[21] Walker, B. J. (2003). The cultivation of student self-efficacy in reading and writing. Reading \& Writing Quarterly: Overcoming Learning Difficulties, 19, 173-187.

[22] Zeidner, M. (1998). Test anxiety: the state of the art. NY: Plenum Press. 